\title{
Maria, um perfil evangelizador que liberta
}

\author{
Mary, an evangelizing profile that sets free
}

\begin{abstract}
Vera Baldez Boing
"O renascimento da humanidade começou de uma mulher, por isso, se quisermos dar humanidade aos nossos dias, devemos recomeçar da mulher". ${ }^{1}$
\end{abstract}

\section{Resumo}

Apresentamos, a partir do pensamento do Papa Francisco, a piedade popular como expressão de uma espiritualidade transformadora e encarnada. Destacamos Maria no centro da experiência libertadora da evangelização inculturada, revelada nas práticas da devoção popular. Uma ação dinamizada pela abertura pessoal à experiência do Espírito Santo. Uma práxis que provoca a conversão das relações humanas. Associamos a luta das mulheres pela dignidade de viver livremente com a coragem e confiança que Maria deposita no amor de Deus, uma vida entregue, em oração, na alegria e na dor, deixandose ser conduzida pela ação do Espírito Santo. Assim, as mulheres que olham para Maria na dor e na oração também entregam suas vidas ao amor de Deus, confiantes na superação dos desafios impostos à condição de ser mulher numa sociedade estruturalmente patriarcal. A peregrinação torna-se um caminho de diálogo e de escuta da presença reveladora de Deus na história cotidiana das relações sociais e pessoais. À luz do ensinamento de Francisco, um perfil

\footnotetext{
${ }^{1}$ FRANCISCO, PP., Homilia da Santa Missa na solenidade de Santa Maria, Mãe de Deus, $1^{\circ}$ de janeiro de 2020.
} 
mariano que evangeliza e transforma tem foco na conversão de mentalidades e atitudes que contribua na construção de uma nova cultura social, mais humanizada e fraterna das relações sociais.

Palavras-chave: Piedade Mariana. Inculturação. Evangelização. Libertação. Sujeito eclesial e social.

\begin{abstract}
This article analysis popular piety as a transforming expression of embodied spirituality, in the light of Pope Francis's thought. It highlights Mary at the centre of the liberating experience of inculturated evangelization revealed in the practices of popular devotion. An action dynamized by personal openness to the experience of the Holy Spirit. A praxis that brings about the conversion of human relationships. We associate the struggle of women for the dignity of living freely with the courage and trust that Mary places in the love of God, a life given, in prayer, in joy and pain, always letting oneself be led by the action of the Holy Spirit. Thus, women who look to Mary in pain and prayer also give their lives to God's love, confident in overcoming the challenges imposed on the condition of being a woman in a structurally patriarchal society. The pilgrimage becomes a path of dialogue and listening to the revealing presence of God in the daily history of social and personal relationships. In the light of Francis, a Marian profile that evangelizes and transforms focuses on the conversion of mentalities and attitudes that contribute to the construction of a new social culture, more humanized and fraternal in social relations.
\end{abstract}

Keywords: Marian piety. Inculturation. Evangelization. Liberation. Ecclesial and social subject.

\title{
Introdução
}

Nossa proposta é desenvolver, a partir do pensamento do Papa Francisco, a força transformadora da devoção a Maria, a piedade popular, para a nova evangelização. Uma exigência que caracteriza diferentes sujeitos coletivos, ativos e promotores de uma renovação missionária. Nesse horizonte, desejamos 
centralizar a presença revolucionária das mulheres, presença massiva na devoção popular, que, à luz de Maria, confiam na superação das injustiças que marcam a condição de ser mulher.

Sem querer correr o risco de reduzir a evangelização ao papel da mulher, desejamos investir e insistir, ao lado de Francisco, na conversão das mentalidades e das atitudes que conduzirão à transformação de uma práxis eclesial e a uma radical urgência de mudanças nas relações humanas entre homens e mulheres, uma nova abordagem na vivência eclesial. ${ }^{2}$ Uma Igreja aberta ao mundo, convocada a viver "o dinamismo de saída" 3 e, assim, tomar a iniciativa da inclusão e do amor, "ir ao encontro, chegar às encruzilhadas dos caminhos para convidar os excluídos". ${ }^{4}$ Aqui, Maria, a Mãe de Deus, será a referência ao desafio das encruzilhadas, uma real possibilidade da inclusão social da mulher, fortalecida pelo reconhecimento da dignidade de toda pessoa humana, presente nos Documentos da Igreja e conferências eclesiais, que o Papa Francisco reforça e evidencia. Dá-se a esse reconhecimento a condição inerente à vida humana: a liberdade e a responsabilidade, ${ }^{5}$ oferecidas, à luz da tradição judaico-cristã, no ato da criação, coloca o ser humano como construtor da obra criadora de Deus, fazendo-o sentir-se chamado a se tornar sujeito de sua própria história.

\section{Um desafio antropológico ${ }^{6}$}

Pensar o ser humano à luz do cristianismo é poder assumir para si a noção de ser sujeito social e eclesial. Assim como Maria, assumir a condição de ser mulher, livre, aberta, em comunicação com o Espírito de Deus, o que a fez da "ação evangelizadora de Maria em relação à promoção humana, a de afirmar e dignificar a pessoa, especialmente a mulher". ${ }^{7}$ E como "não existe sujeito sem autonomia, ou seja, indivíduos capazes de discernir, decidir e agir", ${ }^{8}$ é preciso partir de uma visão que se constrói em um processo de crescimento e inserção na

\footnotetext{
${ }^{2}$ AGUDELO, M., O compromisso da Igreja na emancipação da mulher, p. 125.

${ }^{3}$ EG 20.

${ }^{4} \mathrm{EG} 24$.

${ }^{5} \mathrm{DH} 1$.

${ }^{6}$ Este subtítulo foi desenvolvido a partir da tese defendida pela autora: BOING, V. M. L. B., Novo Sujeito Apostólico.

${ }^{7}$ DSD 416.

${ }^{8}$ PASSOS, D. J., Não há Igreja sem sujeito, p. 27.
} 
vida social do ser humano. Na liberdade que Maria foi capaz de acolher e decidir, em diálogo, o convite do Pai, abrindo, assim, a possibilidade da histórica salvação de Deus no mundo. Francisco expressa o desejo concreto da Igreja ser fonte dessa possibilidade, de devolver ao ser humano a condição de sujeito livre e ativo da sua própria história, social e eclesial. Ser "sujeito da evangelização, porém, mais do que uma instituição orgânica e hierárquica é, antes de tudo, um povo que peregrina para Deus [...] ser fermento de Deus no meio da humanidade". ${ }^{9}$ Um acontecimento realizado na história, nas relações interpessoais que expressam o dinamismo da evangelização movida pela ação do Espírito Santo, que assegura a possibilidade da conversão pessoal, social e eclesial.

Vivemos tempos em que o amor perdeu a força de sua alteridade, diante de uma sociedade globalizada que colocou tudo nas condições do bem-estar material, do conforto e da segurança. ${ }^{10}$ Estamos sob a ameaça de negar o amor como uma intensa e radical experiência de vida, de doação e de crescimento humano. Talvez estejamos vivendo a grave crise de não nos reconhecermos como humanos, capazes de atos humanizados. Pelo contrário, identificados pela violência naturalizada como um instinto. É fundamental revisitar o amor, concretizar atos humanizadores, para revisitar o risco e a aventura, em oposição à segurança e ao conforto, ${ }^{11}$ para recolocar o amor no horizonte do Criador. Reencontrar em Deus a liberdade de amar com os riscos que a vida nos impõe e experimentar o amor como o sopro de um "espírito orante, livres da asfixia de uma imanência fechada". ${ }^{12}$ São as experiências do amor que nos permitem acreditar que podemos ser salvos da escravidão de nossa liberdade. Lançarmo-nos ao destino de nossa humanidade. Como em Puebla foi afirmado, a mãe que plasma seus filhos com o amor da gratuidade de Deus em cada dia de nossas vidas, ${ }^{13}$ resgatando-nos da armadilha reducionista da falsa segurança de uma felicidade consumista.

É importante lembrar que a ideia de pessoa, para o cristianismo, vem da "experiência dialógica na relação entre Deus e o ser humano". ${ }^{14}$ No caminho para pensar a pessoa e o processo de sua formação é importante reconhecer a alteridade e a autonomia como conceitos estruturantes para a antropologia

\footnotetext{
${ }^{9}$ EG 111 e 114.

${ }^{10}$ BADIOU, A.; TRUONG, N., Elogio ao amor, p. 13.

${ }^{11}$ BADIOU, A.; TRUONG, N., Elogio ao amor, p. 13.

${ }^{12}$ GE 147.

${ }^{13}$ DP 290.

${ }^{14}$ RUBIO, A. G., Unidade na pluralidade, p. 304.
} 
integrada, base para o sujeito eclesial e social. Portanto, considerar o caminho dialógico como construtor do processo de libertação.

A tarefa de constituir-se livre não é simples diante de uma sociedade individualista, marcada pelo utilitarismo das relações humanas. Precisamos resgatar a identidade inerente ao cristianismo, restabelecer os laços que foram instituídos por Jesus Cristo nas relações de vida experimentadas, principalmente entre os pobres, descobrir a misericórdia do amor de Deus. Resgatar o dom da criação. Na relação com o outro, nos colocamos em movimento, despertamos a consciência da nossa existência. No processo dessa relação dialogal, de comunicação, nasce uma consciência individual, de um reconhecimento pessoal de identidade, e outra social, que promove a construção da liberdade e da identidade coletiva desenvolvida no contexto histórico em que o ser humano amadurece. ${ }^{15}$

Reforçamos, aqui, que, no processo de amadurecimento, o desenvolvimento da autonomia é acompanhado pela evolução da consciência entre a ação e a reflexão. Ou seja, o saber discernir, tão essencial à ação do Espírito Santo que nos mobiliza como comunidade de fé. Essa compreensão ajuda a considerar a comunidade como lugar de construção da autonomia, um ambiente de crescimento humano, integração e fortalecimento da identidade contra a possível alienação e reducionismo de uma subjetividade fechada. ${ }^{16}$ Lugar de humanização, de construção fraterna. É o que pretendemos fortalecer nas questões que tangem aos desafios eclesiais, essencialmente a presença e a valorização das mulheres, à "exemplo de Maria participante e decisiva na história da humanidade" ${ }^{17}$

Uma mudança exigida à evangelização, a conversão da consciência pessoal e coletiva, ${ }^{18}$ é reforçada por Francisco ao lembrar a mudança da mentalidade cultural que nasce de um processo educativo, inclusive espiritual. ${ }^{19}$ Puebla recorda que Maria "precisa ser cada vez mais a pedagoga do Evangelho na América Latina [...] uma realidade tão profundamente humana e santa que desperta nos crentes as preces da ternura, da dor e da esperança". ${ }^{20} \mathrm{Na}$ condição de mulher, Maria oferece as próprias disposições

\footnotetext{
${ }^{15}$ GESCHÉ, A., O sentido, p. 50.

${ }^{16}$ RUBIO, A. G., Unidade na pluralidade, p. 308.

${ }^{17}$ AGUDELO, M., O compromisso da Igreja na emancipação da mulher, p. 126.

${ }^{18} \mathrm{EN} 18$.

${ }^{19}$ LS 210.

${ }^{20}$ DP $290-291$.
} 
presentes na sua existência: a ternura, a solidariedade, o afeto, a acolhida, o respeito, o silêncio amoroso e a dor do sofrimento transformada na força da ação, movida pelo Espírito Santo, em plena comunhão com o amor de Deus e do Filho. "São valores profundamente humanos que manifestam o rosto de um Deus-Mãe, valores adquiridos com a prática cotidiana na casa entre os entes queridos, mas com perspectiva à gestação da casa grande, da família grande: do povo, da sociedade humana". ${ }^{21}$

O Papa Francisco convida-nos a estar atentos aos sinais dos tempos, ${ }^{22}$ a procurar caminhos possíveis e criativamente responsáveis para encontrar as respostas aos desafios atuais. A exclusão e a injustiça social, como destaca o Papa ao abordar a ausência de um projeto que alcance a todos, são problemas atuais que negam o próprio direito à existência. ${ }^{23}$ Pior, são subtraídos da grande maioria os direitos fundamentais "persistindo inúmeras formas de injustiça, alimentadas por visões antropológicas redutivas e por um modelo econômico fundado no lucro, que não hesita em explorar, descartar e até matar". ${ }^{24}$ É por tudo isso que a Igreja se sente interpelada pelas reinvindicações de uma presença ativa da mulher, tanto no mundo, como no interior da Igreja. Lembra-nos na Exortação Evangelii Gaudium o paradoxo entre o abandono e a resistência das mulheres que se encontram distantes de viver os direitos humanos proclamados socialmente: "duplamente pobres são as mulheres que padecem situações de exclusão, maus-tratos e violência [...] entre elas encontramos continuamente os mais admiráveis gestos de heroísmo cotidiano na defesa e no cuidado da fragilidade das suas famílias". ${ }^{25}$

Nessa perspectiva de libertação, o Papa Francisco coloca a Igreja na fronteira do debate sobre o papel do laicato na ação missionária. Aborda o tema de forma clara e desafiadora à Igreja que, fechada em si mesma, intimista, submete os leigos e leigas a funções secundárias, reforçando uma submissão ao poder clerical. De maneira mais direta, às mulheres que testemunham a autenticidade da fé cristã no mundo, diante da dor a que são submetidas pelas desigualdades de gênero. A proposta de Francisco é pautada pela urgência de uma evangelização capaz de dialogar e, por isso, incluir. A evangelização fundamenta o novo estilo missionário proposto pelo Papa, um protagonismo

\footnotetext{
${ }^{21}$ BREMER, M., Mulher, p. 135.

${ }^{22}$ EG 51.

${ }^{23}$ FT 15-17.

${ }^{24}$ FT 22.

${ }^{25}$ EG 212.
} 
a quem se destina um lugar diferenciado na Igreja e no mundo, os leigos, que têm força para desenvolver sua missão após o Concílio Vaticano II. ${ }^{26}$

As dimensões apresentadas por Francisco são tratadas largamente nos documentos pontifícios e nos pronunciamentos que faz e abarcam a perspectiva da Igreja libertadora, salvífica, centrada na intrínseca relação entre fé e vida, a dimensão da inculturação. Na perspectiva do Papa, tratamos a piedade popular como lugar de uma evangelização renovadora e, por isso, de formação dialogada, dinamizada pelo Espírito Santo. Essa relação entre fé e vida é fundamental para a construção do novo perfil evangelizador, de responsabilidade da comunidade de fé e do mundo que, em diálogo, abrem espaços à nova configuração de uma Igreja em saída.

Nesse sentido, confiamos que a presença da mulher tem sua luz própria, para que seja inserida numa renovação radical e transformadora das relações humanas, eclesiais, sociais e culturais. Uma legítima, real e necessária emancipação. À comunidade eclesial interessa perceber que "algo novo está ocorrendo no encontro entre as mulheres e a figura de Miriâm de Nazaré". ${ }^{27}$

\section{Piedade popular e Maria: evangelização transformadora}

A piedade popular, destacada pelo Papa Francisco no seu pontificado, é revelada como a força dinamizada pela ação do Espírito Santo na evangelização dos povos, que se caracterizam como diferentes sujeitos coletivos, ativos e promotores de uma renovação missionária. ${ }^{28}$ Há uma força no dinamismo da devoção, que deve ser resgatada para que não apenas os cristãos se libertem de formatos herdados de uma evangelização dominadora, mas também para que o mundo conheça a rica cultura que o povo expressa na sua luta pela libertação. Uma libertação que se estende a toda relação humana na gestação do novo perfil evangelizador proposto na Evangelii Gaudium.

Dessa forma, a renovadora proposta missionária do Papa envolve uma mudança da própria estrutura eclesial e, também, de uma conversão pastoral, "que coloque os agentes pastorais em atitude constante de saída". ${ }^{29}$ Portanto, abertos ao dinamismo da conversão pastoral. O dinamismo do deslocamento é um facilitador no processo da evangelização inculturada. Pela Graça, os

\footnotetext{
${ }^{26}$ LG 30-36.

${ }^{27}$ JOHNSON, E. A., Nossa verdadeira irmã, teologia de Maria na comunhão dos santos, p. 27.

${ }^{28} \mathrm{EG} 122$.

${ }^{29}$ EG 27.
} 
cristãos são impulsionados a anunciar o Evangelho, lugar do encontro com Jesus Cristo. "É privilegiar o diálogo como forma de encontro" ${ }^{30}$ A revelação de Deus, alcançada no cotidiano dos encontros dialogais, produz a experiência do amor de Deus, da justiça proclamada pelo Evangelho, contribui na concreta construção da paz, resultado do amor e do encontro com a pessoa de Jesus Cristo. ${ }^{31}$ A presença do Espírito Santo, que dinamiza a evangelização da piedade popular, evidencia a potência dessa revelação no cotidiano da vida. Fortalece, assim, a unidade na diversidade das pessoas na comunidade, ${ }^{32}$ possibilitandonos compreendê-la como lugar teológico de uma expressão missionária. Essa é a aposta de uma ação que revoluciona a vida pessoal e coletiva, como diz Francisco: "sonho com uma opção missionária capaz de transformar tudo [...] que proporcione mais a evangelização do mundo atual que à autopreservação". ${ }^{33}$ A vida, a concreta realidade que proporciona o encontro com Deus, torna-se lugar privilegiado de atuação dos que se encontram alijados da estrutura eclesial, a exemplo das mulheres. Assim foi a experiência de Jesus ao aproximar-se das mulheres de sua época, "sem receio, tratando-as abertamente sem deixar-se condicionar por nenhum preconceito". ${ }^{34}$ Sentiam-se respeitadas e dignas diante de Jesus, fazendo-se membros da convivência dos seguidores.

A abordagem da piedade popular como expressão missionária exige uma aproximação da relação que Jesus instituiu entre os discípulos e que constituiu os laços da comunidade eclesial. Relações de rupturas, de libertação com o modelo vigente, de modo muito especial nas relações com as mulheres de sua época. A Exortação Evangelii Nuntiandi descreve a presença de valores na religiosidade popular que a pedagogia da evangelização suscita.

Traduz em si tal sede de Deus que só os pobres e os simples podem experimentar; ela torna as pessoas capazes a terem expressões de generosidade. [...] Ela, depois, suscita atitudes interiores que raramente se observam: paciência, sentido da cruz na vida cotidiana, desapego, aceitação dos outros, dedicação, devoção, etc. Em virtude desses aspectos, nós a chamamos "piedade popular". ${ }^{35}$

\footnotetext{
${ }^{30}$ EG 239.

${ }^{31}$ EG 217.

${ }^{32} \mathrm{EG} 131$.

${ }^{33}$ EG 27.

${ }^{34}$ PAGOLA, J. A., Jesus, p. 262.

${ }^{35}$ EN 48.
} 
Temos, portanto, a fonte de uma alteridade que, no encontro com Jesus Cristo, é geradora de vida, de crescimento, amadurecimento e de vitalidade renovada de esperança. Assim Jesus vivia junto com os excluídos, promovia ações que transformavam de forma radical a vida das pessoas e a convivência entre elas, fazia crescer a confiança do amor salvador de Deus. Esse é o lugar de encontro entre Deus e os pobres. "Na América Latina, as mulheres em situações de pobreza e violência preparam o caminho para a descoberta de que Maria era como elas, uma mulher pobre, do povo". ${ }^{36}$

A piedade popular revigora, a cada época da história da Igreja, uma espiritualidade marcada pela mística popular, ${ }^{37}$ e os frutos que florescem, na força da sua evangelização, muitos quase não visíveis, desabrocharão no caminho dessa longa peregrinação. Nascem na força da resistência do povo ao sofrimento, à dor, ao sentimento de abandono, renovando a fé, fortalecendo a comunidade eclesial. Um processo permanente de conversão que a missão favorece na própria evangelização. ${ }^{38}$ Essa realidade missionária revela $o$ potencial de uma identidade da piedade popular, o sujeito coletivo. Um protagonismo que pretendemos dedicar às mulheres que, diante da Graça de Deus, em diálogo com a Palavra anunciada, faz caminho inserido na cultura de sua época, ousa anunciar e testemunhar a força transformadora do evangelho na vida do povo. Na experiência desse caminho se resgata a identidade coletiva do que representa ser mulher. Uma identidade perdida e anulada pela violência da dominação patriarcal.

Dessa maneira, o processo de desenvolvimento do protagonismo acontece quando a experiência de Jesus no meio do seu povo é descoberta como o caminho de evangelização, de conversão. E as mulheres somam a essa experiência evangelizadora o compromisso como uma mudança para construir um novo modelo social e eclesial. Quando a referência de Jesus se torna o paradigma de uma nova forma de ser e de viver em relação ao outro e ao próprio Deus, institui-se, então, uma condição de vida social, econômica e cultural a partir de valores do Evangelho. Jesus inaugurou na sociedade de sua época o sujeito coletivo, o povo de Deus e, hoje, desejamos encontrar esse novo sujeito, protagonista da história que referende a práxis de Jesus Cristo, sujeito eclesial e social. "O coração do Senhor começou a palpitar em Maria [...] Nela, Deus ligou-Se à nossa carne e nunca mais a deixou. Através

\footnotetext{
${ }^{36}$ JOHNSON, E. A., Nossa verdadeira irmã, p. 33.

${ }^{37} \mathrm{EG} 124$.

${ }^{38}$ EG 122.
} 
de Maria, encontramos Deus como Ele quer: na ternura, na intimidade, na carne". ${ }^{39}$

Contudo, essa perspectiva exige um discernimento crítico. O próprio Papa Francisco denuncia o risco de um certo tipo de devoção popular, mais ligada à vivência individual e sentimental da fé, que pode comprometer o processo libertador justamente por não corresponder a uma autêntica piedade popular. Trata-se de uma verdadeira ruptura geracional na passagem da devoção popular, onde parecem ser decisivas as influências da ausência de diálogo familiar, os meios de comunicação, o subjetivismo relativista, o consumismo, a falta de acolhida e cuidado pastoral com os pobres, bem como a pouca criatividade para reinventar a adesão mística da fé num mundo religioso pluralista. ${ }^{40}$

\section{Maria, um estilo evangelizador}

Reconhecemos que o dinamismo central da piedade popular é a ação do Espírito Santo, compreendida como caminho missionário de evangelização. A confiança na ação do Espírito Santo, visível na piedade popular, é a mesma que o povo deposita na revelação da presença de Maria. A mãe de Deus, concedida como mãe da Igreja por Jesus na cruz, revela no povo a mesma força experimentada por Maria e pelos discípulos depois da morte de Jesus Cristo. "Uma fórmula de revelação que manifesta o mistério de uma missão salvífica especial". ${ }^{41}$ Esse grande sinal, revelado no mistério da cruz como a grande esperança que o povo expressa na piedade popular, marca um estilo renovador e evangelizador, o estilo mariano.

"Ela é a Mãe da Igreja evangelizadora; sem ela não podemos compreender cabalmente o espírito da nova evangelização". ${ }^{42}$ A expressa afirmação feita pelo Papa Francisco nos induz a uma atenta investigação sobre o papel de Maria, mulher, mãe, missionária, que sustenta, na coragem e na confiança em Deus, os discípulos após a morte do seu Filho na cruz. Dentre algumas amigas de Jesus, Maria, a mãe de Deus, seguia conduzindo os discípulos e seguidores, assim, como hoje, muitas mulheres à frente de suas famílias, cuidam para

\footnotetext{
${ }^{39}$ FRANCISCO, PP., Homilia da Santa Missa na solenidade de Maria Santíssima Mãe de Deus, $1^{\circ}$ de janeiro de 2021.

${ }^{40}$ EG 70.

${ }^{41}$ EG 285.

${ }^{42}$ EG 284.
} 
mantê-las unida diante de tantos desafios que a globalização trouxe à realidade. Uma sociedade individualista, marcada pelo patriarcalismo, esvazia o pleno sentido da família, da relação paterna, muitas vezes, deixando às mulheres a tarefa de acompanhar sozinhas o processo de desenvolvimento da comunidade familiar.

A mulher encontra em Maria a mulher de fé, um encontro de consolo, afeto e esperança para manter a dignidade de permanecer forte diante das turbulências que a vida reserva aos mais pobres. Maria, aquela que "assegura o aconchego de um lar à nossa busca de justiça". ${ }^{43}$ Ela, que desde jovem depositou a plena confiança no projeto de salvação de Deus para a humanidade, "na sua vida tudo foi plasmado pela presença da misericórdia feita carne". ${ }^{44}$ A narrativa de Francisco coloca-nos, sem dúvida, diante da proposta evangelizadora em que tem o pobre como principal eixo da renovação missionária. O pobre que se faz presente na condição de ser Igreja a serviço. E, ao abordar Maria como figura inspiradora da nova evangelização, reforça uma espiritualidade que aflora após o Concílio vaticano II, a piedade popular. Na presença dessa realidade mística, que acentua sua força no continente da América Latina, valoriza o papel da mulher subjugada pelo sistema do capital, sujeita à desvalorização, a manipulações e a todas as formas de violência, individual e familiar. Também as famílias que, em relação a toda ordem de sofrimento, sentem-se cuidadas enquanto caminham. Ela, Maria, que é parte da identidade do povo peregrino, "compartilha as vicissitudes de cada povo que recebeu o Evangelho e faz parte da sua identidade histórica". ${ }^{45}$

Maria acolheu a missão de ser mãe do seu Filho, colocou-se à disposição como serva, "a serva humilde do Pai, que transborda de alegria no louvor". ${ }^{46}$ A presença de Maria diante do mistério revela a ação do próprio Deus que se manifesta nos mais singelos gestos da vida cotidiana, nas relações humanas que, próximas de Deus, permitem a abertura às graças de Deus. Maria é a missionária "que nos acompanha ao longo da vida, abrindo os corações à fé com o seu afeto materno", ${ }^{47} \mathrm{o}$ sim permanente à vida revelada na confiança que chega pela graça das subjetividades abertas. A disponibilidade do serviço, a gratidão expressa no louvor transbordante das ações de Maria, reforça tê-la

\footnotetext{
${ }^{43} \mathrm{EG} 288$.

${ }^{44}$ MV 24.

${ }^{45}$ EG 288

${ }^{46} \mathrm{EG} 286$

${ }^{47}$ EG 286.
} 
como imagem da mãe da Igreja, uma expressão eclesial revelada no rosto de uma mulher, ponte na comunicação de Deus com a história dos homens. Nela a Igreja confirma o amor de Deus pelos pobres, "inscrito no canto de Maria, o Deus da Aliança derruba os poderosos dos tronos e eleva os humildes. [...] Maria foi embebida do espírito dos pobres do Senhor". ${ }^{48}$

Maria, uma presença guardada na tradição da Igreja e que a cada época suscitou diferentes leituras teológicas e variadas imagens da mulher Maria, que viveu na Galileia a sua história e que marcou, de forma definitiva, a humanidade. Mãe de Deus, mãe da Igreja, do Filho morto na cruz. Destacamos a importância que sua presença tem no dinamismo da missão de uma Igreja em saída, proposta de Francisco, para uma Igreja dos pobres, a continuidade da proposta do Concílio e da teologia pós conciliar nascida no continente da América Latina. A pertinência do tema tem relevância porque "uma tradição viva suscita novas interpretações em harmonia com os contextos em constante transformação". ${ }^{49}$ Portanto, é no entendimento da inculturação que se fortalece a compreensão que as mulheres fazem de Maria no processo de libertação da dominação na qual se encontram submetidas na atual estrutura social. $\mathrm{Na}$ verdade, Maria revela na vida das mulheres, pobres e excluídas, a esperança e a força do potencial transformador. "A história da espiritualidade revela que as mulheres encontraram na oração e na companhia de Maria uma fonte de inspiração, consolo e força, precisamente como mulher e especialmente em tempos de tribulação". ${ }^{0}$

Nesse horizonte compreendemos o caminho proposto pelo Papa Francisco, em que a presença de Maria configura, na experiência da piedade popular, um lugar de vigor à nova evangelização, capaz de abrir novos horizontes nas relações humanas. Como foi aberto no caminho percorrido por Maria que, pela ação do Espírito Santo, revelador do mistério de Deus na vida de Maria, tornou-se conhecida, pela pedagogia de Deus, na vida pública do Seu filho e revelada na cruz. Lugar em que Maria "atesta que a misericórdia do Filho de Deus não conhece limites e alcança a todos, sem excluir ninguém". ${ }^{51}$ Assim, vemos nos diferentes santuários o quanto Maria "reúne ao seu redor os filhos, que com grandes sacrifícios, vêm peregrinos para vê-La e deixar-se olhar por ela. Lá encontram a força de Deus para suportar os sofrimentos e as fadigas

\footnotetext{
${ }^{48}$ GALLI, C. M., Cristo, Maria, a Igreja e os povos, p. 97.

${ }^{49}$ JOHNSON, E. A, Nossa verdadeira irmã, p. 25.

${ }^{50}$ JOHNSON, E. A., Nossa verdadeira irmã, p. 26.

${ }^{51}$ MV 24.
} 
da vida". ${ }^{52}$ Assim, as mulheres vivem a força do poder de se descobrirem potencialmente atuantes.

O estilo que o Papa configura à presença Mariana na evangelização possibilita-nos reconhecer que, hoje, a piedade popular, tão fortemente presente na América Latina, revela sinais do Reino que Jesus anunciou, a solidária resistência, a fraternidade, a esperança de que o Reino já está entre nós.

\section{Da família ao mundo, a força geradora da ternura}

O Papa Francisco sinaliza duas grandezas na condição existencial de Maria que dimensionam a proporção do amor de Deus: a ternura e a humildade..$^{53}$ Condições que revelam a sabedoria de saber lidar com os caminhos escolhidos por Deus. Francisco lembra-nos que o Evangelho de Lucas diz que Maria soube guardar no coração o mistério que lhe fora reservado viver $(\operatorname{Lc} 2,19)$ e que "aprendeu a ser mãe, proporcionando a Jesus saber-Se Filho", ${ }^{54}$ num mútuo aprendizado, como diz, uma relação com base na ternura maternal de Deus. Maria viveu a alegria de servir, atitudes de cuidado e de afeto, mas experimentou a dor e o sofrimento quando "teve o coração trespassado pela espada". ${ }^{55}$ Nesse lugar, também se consumiu com a dor dos pobres e excluídos, por quem o Filho se entregou na cruz, fortalecendo sua presença como sinal de esperança entre todos, mãe da Igreja, "vivendo como ninguém viveu as Bemaventuranças de Jesus". ${ }^{56}$ Animando os discípulos, os seguidores e todos que chegavam maravilhados com a descoberta da fé em Jesus Cristo, como a "a mãe que gera nos filhos a maravilha da fé". ${ }^{77}$

O Papa mostra-nos Maria próxima das dores e sofrimento dos partos de tantos povos ${ }^{58}$ no esforço de superar uma leitura que marcou, na história da Igreja, uma imagem de Maria a serviço da legitimação de papéis que submetem mulheres à passividade, à violência em relação à dominação do homem favorecido numa estrutura patriarcal. De fato, "grande parte da

\footnotetext{
${ }^{52}$ EG 286.

${ }^{53} \mathrm{EG} 288$.

${ }^{54}$ FRANCISCO, PP., Homilia da Santa Missa na Solenidade de Maria Santíssima Mãe de Deus, $1^{\circ}$ de janeiro de 2017.

${ }^{55}$ EG 286.

${ }^{56}$ GE 176.

${ }^{57}$ FRANCISCO, PP., Homilia da Santa Missa na Solenidade de Maria Santíssima Mãe de Deus, $1^{\circ}$ de janeiro de 2019.

${ }^{58}$ EG 286.
} 
teologia tradicional faz dela um meio de manter as mulheres no seu lugar subordinado". ${ }^{59}$ Atualmente, as comunidades eclesiais, mergulhadas na teologia da libertação, podem experimentar a releitura, à luz do Evangelho, do papel que Maria tem na vida da luta do povo, principalmente as mulheres que passam a se identificar com a vida dela,${ }^{60}$ tanto na pobreza como na fé, na confiança no Deus salvador. É nessa perspectiva que a presença de Maria é compreendida nas comunidades: "tem um coração pobre, aberto para Deus. E, seguindo a trilha dos profetas e do seu filho Jesus, Maria anuncia que Deus tem compaixão dos pobres e grita por Justiça". ${ }^{61}$

O pontificado de Francisco destaca a fidelidade do povo à vida de Maria como mãe, esposa, amiga e discípula, comprometida com a continuidade do projeto que o Filho anunciou, a concretização do Reino de Deus, uma realidade de esperança na justiça de Deus. Acolher Maria como mãe é colocá-la no cotidiano das relações humanas, apropriar-se do aconchego de um abraço materno, do colo, da confiança em abrir o coração angustiado e temeroso à mãe. Ouvir e sentir a sua presença é saber escutar a Deus. Buscamos Maria, apoiados na espiritualidade que experimentou, da escuta a Deus, e que guardou no silencio do seu coração as incertezas que o futuro lhe reservava, mas confiante na oração e na contemplação vivida na fé. Assim, desejamos ser conduzidos, como foi Maria, pelo Espírito Santo, na mais profunda liberdade. "Somos um povo com uma Mãe, não somos órfãos". ${ }^{62}$

O caminho da espiritualidade orante, conduzida pelo dinamismo do Espírito Santo, afirma a inculturação da fé como escuta e ação na evangelização, uma atividade que expressa a força de Maria nos acontecimentos históricos do Filho, Jesus Cristo. "A mãe do Evangelho vivente [...] deixou-se conduzir pelo Espírito, por um itinerário de fé, rumo a uma destinação feita de serviço e fecundidade" ${ }^{63}$ sempre atenta e pronta a motivar, a sustentar nas dificuldades presentes, agregando, consolando e abraçando a todos que experimentam o medo, a insegurança da solidão que a dor provoca. ${ }^{64}$

\footnotetext{
${ }^{59}$ JOHNSON, E. A., Nossa verdadeira irmã, p. 31.

${ }^{60}$ JOHNSON, E. A., Nossa verdadeira irmã, p. 33.

${ }^{61} \mathrm{CNBB}$, Com Maria, rumo ao novo milênio, p. 54.

${ }^{62}$ FRANCISCO, PP., Homilia da Santa Missa na Solenidade de Maria Santíssima Mãe de Deus, $1^{\circ}$ de janeiro de 2017.

${ }^{63} \mathrm{EG} 287$.

${ }^{64}$ FRANCISCO, PP., Homilia da Santa Missa na Solenidade de Maria Santíssima Mãe de Deus, $1^{\circ}$ de janeiro de 2019.
} 
O povo tem em Maria a força para a superação das adversidades, do sofrimento, da dor do abandono e da violência a que estão submetidos pelo poder econômico excludente. Uma economia que desvaloriza o lugar da mulher, esvazia de sentido a maternidade e privilegia o lucro, coloca-a como objeto de consumo e de mercadoria. No combate a essa desvalorização da mulher, a toda violência a que é submetida, Francisco reafirma que "o renascimento da humanidade começou de uma mulher, por isso, se quisermos dar humanidade aos nossos dias, devemos recomeçar da mulher" ${ }^{65}$ Vislumbramos, nessa perspectiva do Papa, a inclusão da mulher, das próprias condições que desafiam a vida em família, da violência instaurada pela ausência dos direitos fundamentais. E Maria tornou-se, pela expressão de fé presente na piedade popular, caminho de força e esperança do reino de justiça. A esperança é a força que sustenta o processo de evangelização, a certeza de que Deus caminha junto. ${ }^{66} \mathrm{~A}$ experiência do amor de Deus vivida por Maria fortalece e legitima a presença da mulher em direção à formação de novas identidades. Dessa forma, a identidade individual e a experiência de Deus culminarão na realidade histórica da salvação. ${ }^{67}$ Encontram-se entrelaçadas a experiência de Deus vivida por Maria e as que as mulheres experimentam no processo evangelizador da piedade popular.

A Justiça de Deus está, em Maria, afirmada como esperança real, afinal, nela vimos nascer o salvador. Em Maria, como diz o Papa, o povo se sente protegido e forte para seguir em meio às desesperanças anunciadas por uma sociedade individualista e reducionista, geradora de relações desumanizadoras. ${ }^{68} \mathrm{O}$ clamor do povo a Maria, Mãe de Deus, expressado na piedade popular, revela a resistência contra a desvalorização da mulher, da violência doméstica, do filho que se encontra perdido, enfim, de toda a família, constituída como a primeira e fundamental experiência de amor e de comunidade. Maria, é aquela que ouve, escuta, junto, ao lado de Deus, o clamor por uma sociedade que inclua o direito das mães de poderem criar e sustentar seus filhos. Mães que, "mesmo nos momentos piores, sabem testemunhar a

\footnotetext{
${ }^{65}$ FRANCISCO, PP., Homilia da Santa Missa na Solenidade de Maria Santíssima Mãe de Deus, $1^{\circ}$ de janeiro de 2020.

${ }^{66}$ FRANCISCO, PP., Homilia em Aparecida, 24 de julho de 2013.

${ }^{67}$ JOHNSON, E. A., Aquela que é, p. 104-105.

${ }^{68}$ FRANCISCO, PP., Homilia por ocasião do centenário das aparições da Bem-Aventurada Virgem Maria na cova da Iria, 12-13 de maio de 2017.
} 
ternura, a dedicação incondicional, a força da esperança". 69 "Aproximando-se de Maria, a Igreja reencontra o seu centro e a sua unidade [...] jamais podemos compreender a Igreja, se a olharmos só a partir das estruturas, programas e tendências e não do coração. A Igreja tem coração de mãe". ${ }^{70}$

Reafirmamos, então, o acento a Maria como modelo eclesial, inspirador pela condição da força materna e raiz de toda primeira comunidade que o ser humano experimenta, a família. Acolher Maria "nas nossas casas, nas nossas famílias, nas nossas comunidades, [...] encontrar aquele olhar que nos liberta da orfandade" ${ }^{\prime 11}$ representa um encontro que remete à lembrança de que somos irmãos, um sentimento de pertença, como diz Francisco. Reconhecer na família o potencial evangelizador contribui para que a Igreja receba sujeitos preparados para amar, imbuídos de espiritualidade, confiantes. Há uma intrínseca relação entre família e Igreja. Não há como pensar família, Igreja e mundo sem os ecos recebidos da sociedade, atualmente marcada pelo agravamento de um individualismo exacerbado e da violenta discriminação contra a mulher. Pensar o sujeito, consciente, autônomo e ativo exige considerar uma contínua formação integrada, ${ }^{72} \mathrm{o}$ que exige que a comunidade eclesial valorize a piedade popular com o respectivo potencial de sujeitos em processo de formação. Por isso, a família pode ser percebida, nesse processo, à luz de Maria, como resistência a todo tipo de individualismo que reduz e anula a autêntica formação do sujeito. E que possibilita uma real conversão que liberta a mulher da condição de refém de uma estrutura patriarcal. A sociedade, dessa maneira, recebe o sujeito em processo de transformação social e eclesial, ou seja, "as famílias podem ser uma escola fundamental para a sociedade. [...] A Igreja tem uma missão importante de ajudar as famílias na descoberta dessa postura". ${ }^{73}$ Redescobrir novas relações humanas pautadas no amor e no respeito à dignidade de existir nas diferenças.

\footnotetext{
${ }^{69}$ FRANCISCO, PP., Homilia da Santa Missa na Solenidade de Maria Santíssima Mãe de Deus, $1^{\circ}$ de janeiro de 2017.

${ }^{70}$ FRANCISCO, PP., Homilia da Santa Missa na Solenidade de Maria Santíssima Mãe de Deus, $1^{\circ}$ de janeiro de 2020.

${ }^{71}$ FRANCISCO, PP., Homilia da Santa Missa na Solenidade de Maria Santíssima Mãe de Deus, $1^{\circ}$ de janeiro de 2017.

${ }^{72}$ Ideia desenvolvida pelo autor nos artigos: PASSOS, J. D., Não há Igreja sem sujeito, e PASSOS, J. D., A família como sujeito.

${ }^{73}$ PASSOS, J. D., A família como sujeito, p. 68.
} 
A relação de confiança e autonomia, construída na comunidade familiar, favorece o florescimento de autênticas comunidades de fé, preenchidas de vida, mobilizadas a anunciar a fé em Jesus Cristo Vivo. O Papa convidanos a pensar na situação das famílias, tomar consciência da complexidade no mundo global e assumi-la como lugar de alegria e de aprendizados porque ela é também o júbilo da Igreja. ${ }^{74} \mathrm{E}$ a piedade popular pode oferecer um lugar de formação, de articulação e extensão da família. Um mútuo diálogo evangelizador pode ajudar na superação de limitações de ambos os ambientes.

\section{Conclusão}

Numa perspectiva humanizadora e libertadora, destacamos a piedade popular como lugar de expressão evangelizadora e transformadora. Um processo de inculturação da fé, que contribui para a reflexão social e o discernimento evangélico, que a comunidade eclesial favorece ao protagonismo social - uma relação de crescimento e de amadurecimento da fé. Essa realidade precisa ser defendida e concretizada no interior do processo evangelizador, na vivência de uma espiritualidade encarnada.

O retorno à práxis de Jesus Cristo como lugar da revelação do amor de Deus, que salva e liberta, é fonte da ação missionária que consolida a opção preferencial pelos pobres. Destacamos a centralidade de Maria que referenda a experiência libertadora da graça de Deus na vida humana e na vida das mulheres que, juntas, caminham na certeza da ação salvífica de Deus. Conceber a evangelização, no contexto da globalização excludente, é muito importante para reconhecer na expressão da piedade popular, um cenário do protagonismo social destacado pelo Papa Francisco como potencial transformador. Neste tempo hodierno, repensar as relações humanas no contexto histórico também não é uma tarefa simples. São muitas as feridas que desumanizam e impedem uma participação ativa e comprometida com a realidade. Por isso, é importante conhecer as forças que atuam e neutralizam as lutas por mudanças concretas. Não podemos prescindir do diálogo com o mundo que nos insere nesse processo de crescimento de fé, pessoal e social.

${ }^{74}$ AL 1-2. 
É preciso superar o dualismo existente na própria formação do cristão, para que nesse processo se redescubra a identidade e o papel do Cristianismo na construção de uma realidade mais justa a partir das relações humanas entre homens e mulheres. Sabemos das dificuldades, nesse contexto desordenado, pelo abuso do poder econômico e do patriarcado contra as mulheres, impedidas de autonomia, numa relação de constante dependência que reduz as possibilidades de reconhecimento de sua identidade de gênero. Por isso, focamos a dimensão da antropologia, articulada com a comunidade de fé, que ajuda na configuração do sujeito social e eclesial em vista de uma mudança radical, nas relações e nas estruturas sociais. Esse é um caminho que a Igreja precisa atentar no processo de superação da dicotomia entre fé e vida, pois tem alcance no interior da estrutura missionária da própria comunidade eclesial: o dinamismo da humanização do projeto do Reino.

O que defendemos é a explicitação do dinamismo intrínseco que acontece entre a realidade social e a ação evangelizadora. E favorecer que as vidas se entrelacem a partir da boa notícia do Evangelho de Jesus Cristo. Assim, a piedade popular, na expressão da fé inculturada se revitaliza, configurando uma evangelização transformadora e libertadora. Esse é o caminho que precisamos manter aberto para que a graça do Espírito Santo atue, renove e sustente o processo evangelizador, que conduz à conversão das mulheres à libertação.

Em tempos sombrios, a práxis nos reconduz à nova evangelização, para manifestar o rosto misericordioso de Deus. Trata-se de um caminho que nos coloca no processo de conversão à humanização. Precisamos do discernimento evangélico e da lucidez social para defender o que acreditamos ser saída para uma evangelização atuante e, por isso, renovada: continuar o que Jesus inaugurou - o Reino de Deus - ao concretizar a sua opção pelos marginalizados. Fechando-se em si ou na instituição, o verdadeiro encontro não acontece. É no mundo que muitos têm a oportunidade de conhecer o Deus libertador e o Filho que caminhou, revelando a ação de Deus na história humana. Assim, Ele desperta a fé integrada à vida e ao cotidiano de cada contexto histórico, possibilitando-nos viver a experiência da conversão que nos coloca no horizonte de uma nova existência humana.

A conversão acontece com os pés nessa realidade, muitas vezes, como disse o Papa Francisco, enlameada, suja e marcada pela dor do abandono. Assim, somos libertados de uma fé desenraizada, esvaziada e vulnerável às manipulações. Perceber os sinais dos tempos abre o caminho para uma 
evangelização inculturada e atualizada para comunicar a mensagem de Deus. Acentuamos, na realidade da evangelização transformadora, a esfera social que se estende às mulheres que, são, hoje, violadas na sua dignidade, subtraindo-lhes o direito à vida plena. Aqui, destacamos o concreto caminho na consolidação da proposta renovadora da missão eclesial, em que deve emergir o novo sujeito eclesial e social. E, nesse processo, Maria é a mulher que nos ensina a educar. Promoveu um caminho pedagógico da fé, que alia o amor de Deus ao conhecimento pessoal e à espiritualidade encarnada.

Peregrinar no caminho ao lado de Maria promove a escuta de Deus, faz-nos olhar os encontros que Jesus provocou como construção de uma nova realidade: uma cultura que coloca condições para uma sociedade mais humana e fraterna. Nela, homens e mulheres se libertam das relações de submissão, escravidão que resultam na indiferença, na violência e na invisibilidade do outro. Trata-se de uma proposta que perpassa todo o pontificado de Francisco: o diálogo como caminho formativo da evangelização que educa e estreita laços entre o ser humano e Deus. Concluímos com a significativa afirmação do Papa Francisco sobre as práticas encarnadas das diferentes expressões populares: "têm carne, têm rostos. Estão aptas para alimentar potencialidades relacionais, e não tanto fugas individuais [...] sem compromissos fraternos", ${ }^{75}$ que escravizam e desumanizam, ao contrário de libertar e humanizar.

\section{Referências bibliográficas}

AGUDELO, M. O compromisso da Igreja na emancipação da mulher. In: CAROL, E.; LAURENTIN, R.; AGUDELO, M. A mulher numa estrutura eclesial masculina. Petrópolis: Vozes, 1980. p. 123-131.

BADIOU, A.; TRUONG, N. Elogio ao amor. São Paulo: Martins Fontes, 2013.

BOING, V. M. L. B. Novo Sujeito Apostólico: a dimensão transformadora no Magistério do Papa Francisco. Rio de Janeiro, 2021. 206p. Tese. Faculdade de Teologia, Pontifícia Universidade Católica do Rio de Janeiro. Disponível em: <https://www.maxwell.vrac.puc-rio.br/53879/53879.PDF>. Acesso em: 22 nov. 2021.

${ }^{75}$ EG 90. 
BREMER, M. Mulher. In: AMERÍNDIA (Org.). Globalizar a esperança. São Paulo: Paulinas, 1998. p. 131-138.

CELAM. A evangelização no presente e no futuro da América Latina. III Conferência Geral do Episcopado Latino-americano, Puebla. Petrópolis: Vozes, 1979.

CELAM. Nova evangelização, promoção humana, cultura cristã. IV Conferência Geral do Episcopado Latino-americano, Santo Domingo. São Paulo: Loyola, 1992.

CNBB. Com Maria, rumo ao novo milênio. São Paulo: Paulinas, 1998.

FRANCISCO, PP. Bula Misericordiae Vultus de Proclamação do Jubileu Extraordinário da Misericórdia. São Paulo: Loyola, 2015.

FRANCISCO, PP. Carta Encíclica Fratelli Tutti sobre a fraternidade e a amizade social. São Paulo: Loyola, 2020.

FRANCISCO, PP. Carta Encíclica Laudato Si sobre o cuidado da casa comum. São Paulo: Paulus, Edições Loyola, 2015.

FRANCISCO, PP. Exortação Apostólica Evangelii Gaudium ao episcopado, ao clero, às pessoas consagradas e aos fiéis leigos sobre o anúncio do Evangelho no mundo atual. São Paulo: Paulus / Edições Loyola, 2013.

FRANCISCO, PP. Exortação Apostólica Gaudete et Exsultate sobre o chamado à santidade no mundo atual. São Paulo: Loyola, 2018.

FRANCISCO, PP. Exortação Apostólica Pós-Sinodal Amoris Laetitia aos bispos, aos presbíteros e aos diáconos, às pessoas consagradas, aos esposos cristãos e a todos os fiéis leigos sobre o amor na família. São Paulo: Paulus / Edições Loyola, 2016.

FRANNCISCO,PP. Homilia da Santa Missa na Solenidade de MariaSantíssima Mãe de Deus, $1^{\circ}$ de janeiro de 2017. Disponível em: $<$ https://www.vatican.va/ content/francesco/pt/homilies/2017/documents/papa-francesco_20170101_ omelia-giornata-mondiale-pace.html>. Acesso em: 22 nov. 2021.

FRANCISCO, PP. Homilia da Santa Missa na Solenidade de Maria Santíssima Mãe de Deus, $1^{\circ}$ de janeiro de 2019. Disponível em: $<$ https:// www.vatican.va/content/francesco/pt/homilies/2019/documents/papafrancesco_20190101_omelia-giornatamondiale-pace.html $>$. Acesso em: 22 nov. 2021. 
FRANCISCO, PP. Homilia da Santa Missa na solenidade de Santa Maria, Mãe de Deus, $1^{\circ}$ de janeiro de 2020. Disponível em: $<$ https://www.vatican.va/ content/francesco/pt/homilies/2020/documents/papa-francesco_20200101_ omelia-madredidio-pace.html>. Acesso em: 22 nov. 2021.

FRANCISCO, PP. Homilia da Santa Missa na solenidade de Santa Maria, Mãe de Deus, $1^{\circ}$ de janeiro de 2021. Disponível em: $<$ https://www.vatican.va/ content/francesco/pt/homilies/2021/documents/papa-francesco_20210101_ omelia-madredidio-pace.html>. Acesso em: 22 nov. 2021.

FRANCISCO, PP. Homilia por ocasião do centenário das aparições da Bem-Aventurada Virgem Maria na cova da Iria, 12-13 de maio de 2017. Disponível em: <https://www.vatican.va/content/francesco/pt/homilies/2017/ documents/papa-francesco_20170513_omelia-pellegrinaggio-fatima.html>. Acesso em: 22 nov. 2021.

GALLI, C. M. Cristo, Maria, a Igreja e os povos: a mariologia do Papa Francisco. Brasília: Editora da CNBB, 2018.

GESCHÉ, A. O sentido. São Paulo: Paulinas, 2005.

JOHNSON, E. A. Aquela que é. Petrópolis: Vozes, 1995.

JOHNSON, E. A. Nossa verdadeira irmã: Teologia de Maria na comunhão dos santos. São Paulo: Loyola, 2006.

PAGOLA, J. A. Jesus: aproximação histórica. Petrópolis: Vozes, 2010.

PASSOS, J. D. Não há Igreja sem sujeito. In: GRUPO DE REFLEXÃO DA COMISSÃO EPISCOPAL DE PASTORAL PARA O LAICATO DA CNBB. Sujeitos eclesiais: sal da terra e luz do mundo: reflexões sobre o Documento 105: Ano Nacional do Laicato. São Paulo: Paulinas, 2017. p. 27-35.

PASSOS, J. D. A família como sujeito. In: OBSERVATÓRIO ECLESIAL DO BRASIL. Todos somos discípulos missionários. São Paulo: Paulinas, 2017. p. 59-68.

PAULO VI, PP. Exortação Apostólica Evangelii Nuntiandi sobre a evangelização no mundo contemporâneo. São Paulo: Paulinas, 2004.

PAULO VI, PP. Carta Encíclica Dignitatis Humanae sobre a dignidade humana. Petrópolis: Vozes, 1965.

RUBIO, A. G. Unidade na pluralidade. 3.ed. São Paulo: Paulus, 2001. 
CONCÍLIO VATICANO II. Constituição Dogmática Lumen Gentium sobre a Igreja. In: CONCÍLIO VATICANO II. Compêndio do Vaticano II: constituições, decretos, declarações. 29.ed. Petrópolis: Vozes, 2000. p. 39-113.

Vera Baldez Boing Doutora em Teologia pela Pontifícia Universidade Católica do Rio de Janeiro Docente do Departamento de Teologia da Pontifícia Universidade Católica do Rio de Janeiro Rio de Janeiro / RJ - Brasil E-mail: verabaldezboing@gmail.com

Recebido em: 31/07/2021 Aprovado em: 22/11/2021 